\title{
MAKNA SIMBOLIS \\ TARI MAYANG RONTEK \\ DI KABUPATEN MOJOKERTO
}

\author{
Windi Dwi Setya Agustin \\ Institut Seni Indonesia (ISI) Surakarta \\ Jalan Ki Hadjar Dewantara No.19, Kentingan, Jebres, Surakarta 57126 \\ Sri Hadi \\ Institut Seni Indonesia (ISI) Surakarta
}

Abstract

This research focuses on the symbolic meaning contained in the Mayang Rontek dance. Mayang Rontek Dance is an entertainment dance that was rushed by the young women. The problem in this research is how the idea of Mayang Rontek dance in Mojokerto Regency?. How to form Mayang Rontek dance performances in Mojokerto?. And how the symbolic meaning of Mayang Rontek dance in Mojokerto Regency?. The research was conducted with qualitative research with using a descriptive analysis method used to and analyzing the dance and technique of Mayang Rontek Library, observation and interview data collection. Analyzing the line using the concept of Rahayu Supanggah stating that the garrison involved several elements of mutual such as: Garap, penggarap, facility, furniture or dear and a crisp consideration. To analyse the shape with the concept of a form of Suzanne K With the theories of elements in the dance expressed by the Sumandiyo Hadi. To explain the symbolic meaning of dance Mayang Rontek. The theory of Roland Barthes states that symbols on Objects not only carry information, but also conjugation Structured system of the mark. The results of the research are known to working on idea originated from Manten Mojoputri composed by Setu den other Mojokerto artists. Mayang Rontek Dance contains symbolic significance about the values life. It is included in elements such as: motion, Accompaniment/poetry, dancer, fashion and title. Moreover motion in dance Mayang Rontek is a new style taken from a variety of movements Remo Jombang, Remo Surabaya and Beskalan.

Keywords: Mayang Rontek, Garap, form, Setu, symbolic meaning.

\section{PENDAHULUAN}

Kabupaten Mojokerto adalah salah satu wilayah di Jawa Timur yang tiada jauh berbeda dengan Kota Mojokerto khususnya dalam bidang ragam corak budaya yang memiliki nilai-nilai sejarah yang banyak pengaruh dari Kerajaan Majapahit (abad 13-15). Manten Mojoputri merupakan prosesi pernikahan pada masa kerajaan Majapahit. Sekarang prosesi manten Mojoputri tersebut sudah semakin jarang ditemui bahkan sudah tidak ada lagi yang menggunakan prosesi manten Mojoputri. Salah satu ragam budaya dengan latar belakang kerajaan Majapahit adalah tari Mayang Rontek. Tari Mayang Rontek 
merupakan bentuk revitalisasi dari prosesi Bedhol Manten Mojoputri. Tari ini diciptakan sebagai pelengkap dalam prosesi manten Mojoputri. Walaupun Upacara Mojoputri sudah tidak dilakukan tapi Tari Mayang Rontek masih tetap ditampilkan sebagai tari lepas (Setu,wawancara-28-032018). Hal tersebut membuat penulis tertarik untuk meneliti bagaimana ide garap tari Mayang Rontek di Kabupaten Mojokerto.

Ide garap tari Mayang Rontek berawal dari gagasan untuk menciptakan sebuah tarian yang dapat digunakan setelah prosesi temu manten Mojoputri. Machmoed Zai memberi saran kepada Setu seniman Mojokerto untuk menciptakan sebuah karya tari yang dapat digunakan setelah proses bedhol manten Mojoputri. Maka atas saran tersebut lahir sebuah tari Mayang Rontek di tahun 1993 dengan merivitalisasi manten Mojoputri (Setu, wawancara 28-032018).

Tari Mayang Rontek termasuk dalam kategori tari rakyat yang bertemakan doa dan harapan untuk menjalani hidup dengan baik. Nama Mayang Rontek diambil dari ubohrampe (ubohrampe adalah sarana atau prasarana) temanten, "Mayang diambil dari sekar mayang yang mempunyai arti tongkol bunga atau dalam bahasa Jawa disebut kembang" dan "rontek adalah hiasan di atas tombak yang berbentuk rumbai- rumbai". Jadi arti dari nama Mayang Rontek adalah sebuah kembar mayang yang terdiri dari rontek-rontek atau rumbai-rumbai yang berbentuk kembang (bunga) sebagai bunga persembahan dalam pernikahan (Setu, wawancara 28-03-1028).
Tarian ini awalnya ditampilkan dalam acara manten Mojoputri yang berfungsi sebagai penyambutan dan sebagai media penyampaian pesan kehidupan. Setelah tahun 1996 tari ini dijadikan tari khas Kabupaten Mojokerto dan sering dipentaskan dalam acara resmi atau tidak resmi di Kabupaten Mojokerto. Tari Mayang Rontek mempunyai makna simbolis tentang kehidupan yang terkandung dalam elemenelemen tari, antara lain: gerak, musik, kostumpenari dan judul.

Gerak dalam tari Mayang Rontek mengambil perpaduan antara gerak Jombangan, gerak Surabayan dan gerak Malangan. Gerak gaya Jombangan diambil dari gerak Remo Jombang yaitu: 1) gerak tangan iket pada Remo Jombang yang di kembangkan lagi menjadi gerak tumpang tali jombangan dan volumenya disesuaikan untuk gerak tari putri. Sedangkan gerak gaya Surabayan diambil dari beberapa gerak Remo Surabaya putra dan putri, antara lain: 1) Tanjak pada remo putri diambil dan disederhanakan, 2) gerak tumpang tali pada tari remo putri yang dikembangkan menjadi tumpang tali suroboyoan, 3) kencrongan yang dikembangkan. Gerak-gerak dalam tari Mayang Rontek yang dikembangkan lagi oleh Setu mempunyai makna simbolis tertentu, Misalnya: pada bagaian pembuka mempunyai makna berdoa dan harapan, bagian kedua mempunyai makna kehidupan yaitu perjalanan hidup, dan bagian penutup mempunyai makna penyelesaian atau jalan keluar. Ragam gerak tari ini tidak terlalu banyak dan sederhana, ragam gerak mengalami pengulangan $2 x$, hal ini mempunyai maksud 
dan makna tersendiri (Setu, wawancara 2803-2018).

Tari Mayang Rontek ditarikan oleh remaja putri, hal ini dikarenakan Setu ingin menggambarkan manten putri dalam manten Mojoputri. Tarian ini bisa ditarikan tunggal ataupun kelompok, yang jika ditampilkan dalam bentuk kelompok biasanya berjumlah ganjil minimal 5 dan maksimal 9 orang yang mempunyai makna tertentu (Setu, wawancara 28-03-2018). Menurut pendapat Anita tari ini bisa ditarikan oleh remaja putri dari tingkat SMP hingga SMA (Anita, wawancara 11-01-2019).

Iringan tari Mayang Rontek menggunakan gamelan Jawa Timuran dengan laras slendro dan terdiri dari beberapa gendhing Jawa Timuran, yaitu Srepek Suroboyo, Jula-juli, Giro jaten dan terbangan. Gendhing Girojaten biasanya digunakan saat temanten Mojoputri prosesi temu manten/pangasih. Iringan tari Mayang Rontek juga terdapat syair atau vocal yang berisi tentang parikan-parikan yang mempunyai makna tentang kehidupan (Sumaraji, wawancara 28-03-2018).

Ketertarikan penulis dalam tari Mayang Rontek terletak pada latar belakang garap, bentuk pertunjukan serta makna simbolis yang terkandung dalam elemenelemen tari Mayang Rontek. Ide garap tari Mayang Rontek berawal dari saran Machmoed Zain selaku Bupati Mojokerto pada tahun 1993, ia meminta Setu dan seniman lain untuk menggarap karya tari yang dapat dipentaskan setelah prosesi bedhol manten mojoputri. Setelah itu pada tahun 1996 oleh pemerintah kabupaten tari Mayang Rontek dijadikan tarian khas dari kabupaten Mojokerto. Ketertarikan selanjutnya terletak pada bentuk pertunjukan tari Mayang Rontek, dimana tarian ini ditarikan oleh remaja putri yang dapat ditarikan tunggal ataupun kelompok. Tarian ini menggunakan gamelan Jawa Timuran dengan tambahan rebana untuk memunculkan kesan dinamis, dengan kostum yang tertutup seperti kebaya lengan panjang, jarik panjang, penutup gelung pengganti jilbab, serta menggunakan aksessoris rontek. Ragam gerak tari ini mengambil dari gerak tari yang sudah ada seperti Remo Jombang, Remo Surabaya dan Beskalan Malang. Gerak tersebut oleh Setu dikembangkan dan menjadi gaya baru yang menjadi gaya Mojokerto. Hal yang menarik selanjutnya adalah makna simbolis yang terkandung dalam elemen-elemen tari Mayang Rontek. Simbol-simbol yang ada mengandung makna tentang kehidupan manusia, dimana sebagai manusia haruslah mempunyai akhlak yang terpuji dan mempunyai rasa rendah hati karena diatas langit masih ada langit.

Bagi masyarakat Mojokerto tari Mayang Rontek dalam manten Mojoputri hanya sebagai tari penyambutan setelah bedhol manten, walaupun tari Mayang Rontek dalam Mojoputi hanya untuk hiburan tetapi tari tersebut mengandung pesan yang baik untuk mempelai pengantin dalam memulai bahtera rumah tangga yang dipercayai oleh masyarakat. Selain itu tari Mayang Rontek juga sering dipentaskan dalam acara HUT Kabupaten Mojoketo sebagai tarian khas dari kabupaten Mojokerto yang mempunyai fungsi sebagai hiburan (Anita, wawancara 11-01-2019). 
Terkaitan dengan hal tersebut, maka Makna Simbolis Tari Mayang Rontek di Kabupaten Mojokerto menarik untuk dikaji lebih lanjut karena berdasarkan pengamatan penulis belum ada yang menulis dalam bentuk makna simbolis dari tari Mayang Rontek.

\section{MAKNA SIMBOLIS DALAM ELEMEN- ELEMEN TARI MAYANG RONTEK}

Daerah Mojokerto pada tahun sekitar 16 sering melakukan prosesi manten Mojoputri oleh masyarakat setempat, seiring dengan berkembangnya zaman sekarang sudah tidak pernah dijumpai prosesi manten mojoputri. Tahun 1996 hingga sekarang tari Mayang Rontek menjadi tari khas dari Kabupaten Mojokerto yang sering tampil untuk acara resmi dan tidak resmi.

Roland Barthes menyatakan bahwa simbol pada objek-objek tidak hanya membawa informasi, tetapi juga mengkontitusi sistem terstruktur dari tanda (Kurniawan, 2001:53). Mengkonstitusi disini adalah sebuah wujud makna simbolis dari elemen-elemen yang terdapat pada tari Mayang Rontek yang sudah disusun oleh senimannya atau koreografer, yang kemudian oleh masyarakat digunakan sebagai ungkapan rasa doa dan harapan. Di setiap elemen-elemen tari terdapat simbol yang mempunyai makna simbolis masingmasing.

Peneliti menggunakan pendekatan hermeneitik untuk mencari makna-makna simbolis yang dikaji. Peneliti menafsirkan setiap kata atau istilah pada elemen-elemen sajian tari Mayang Rontek. Penafsiran dilakukan setelah mewawancarai koreografer serta informasi dari buku, tarfsiran kemudian dikaitkan dengan tafsir peneliti dan tafsir pencipta atau koreografer. Menurut Sumandiyo Hadi elemen-elemen tari meliputi; gerak tari, ruang tari, iringan tari, judul tari, tema tari, jenis tari, mode penyajian, jumlah penari dan jenis kelamin, rias dan kostum tari serta properti tari serta kelengkapan lainnya (2003: 86). Dari pernyataan Sumandiyo tersebut penulis mengambil beberapa elemen yang mempunyai makna simbolis dalam tari Mayang Rontek antara lain; Gerak tari, Musik tari, Kostum tari, Penari dan Judul tari.

\section{MAKNA SIMBOLIS GERAK DALAM TARI MAYANG RONTEK}

Ragam gerak tari Mayang Rontek menggunakan ragam gerak yang sudah ada, yaitu perpaduan antara gerak gaya Jombangan, gerak gaya Surabayan dan gaya Malangan yang dikembangkan lagi. Karena Mojokerto sendiri belum mempunyai ciri gerak yang khas, jadi oleh Setu mengambil dari gaya daerah yang dekat dengan Mojokerto yaitu sebelah barat perbatasan dengan daerah Jombang yang terkenal dengan tari Remo Bolet, Remo Jombang, di sebelah timur daerah Surabaya yang terkenal juga dengan Remonya dan sebelah selatan berbatasan dengan Malang yang terkenal dengan tari Topeng dan tari Beskalan. Dengan demikian dalam tari Mayang Rontek muncul ragam gerak yang baru dan mempunyai makna sendiri. Walaupun gerak-gerak Tari Mayang Rontek banyak diambil dari gerak Remo, tapi Tari Mayang Rontek berbeda yaitu gerakannya dinamis tetapi tetap lembut (Setu, wawancara 28-03-2018). 
Tari Mayang Rontek memiliki 3 struktur sajian yang berurutan secara ritmis dan dinamis, antara lain: bagian 1 (pembuka), bagian 2 (inti), dan bagian 3 (penutup).

\section{Bagian 1 (Pembuka)}

Pada bagian pertama atau pembuka menggunakan gendhing giro jaten yang memiliki suasana rasa agung, yang didukung dengan ragam gerak: mlampah songgo nogo, bukak ngawar kanan/kiri, nogo mangap, mlampah ngloro, singget dan mlampah prapatan. Pada bagian ini menyimbolkan doa atau manembah kepada Tuhan, yang bermakna bahwa sebagai manusia harus senantiasa untuk selalu berdoa dan berserah diri kepada Tuhan agar semua keinginan dan harapan dapat tercapai dengan baik, serta menjadikan manusia yang taat kepada Tuhan dengan selalu menjalankan perintahnya dengan baik dan meninggalkan hal-hal yang buruk yang dilarang oleh Tuhan. Jika kita mampu menjalankan hal-hal yang baik tersebut maka Tuhan juga akan memberikan jalan yang mudah untuk menghadapi segala macam cobaan dan bahaya.

Pada bagian pertama atau pembuka dalam gerak tari Mayang Rontek mempunyai makna simbolis dari doa atau manembah yang dapat dilihat pada gerakgerak bentuk tangan yang lebih lembut, kalem, tenang dan lebih menonjolkan suasana agung yang didukung dengan gendhing giro jaten. Makna tersebut diuraikan dalam ragam gerak antara lain:

a. Mlampah songgo nogo (Lengan kanan lurus ke samping sejajar dengan perut, jari-jari menghadap ke atas. Lengan kiri ditekuk ke samping sejajar dengan kepala membentuk siku dengan telapak tangan menghadap ke atas. Posisi badan menghadap depan, pandangan lurus ke depan. Kedua tumit merapat dan kaki Mendhak.). Menyimbolkan berdoa kepada Tuhan Yang Maha Esa. Mempunyai makna sebagai manusia ciptaan-Nya kita harus ingat dan berserah diri kepada Tuhan, agar semua keinginan dapat terwujud.

b. Bukak nggawar kanan/kiri (Lengan kanan lurus ke samping kanan bawah sejajar dengan pinggang, lengan kiri ditekuk ke arah dalam di depan pusar mengarah ke kanan. Kedua telapak tangan menghadap ke dalam (dilakukan sebaliknya). Tolehan kepala mengikuti pergerakan lengan yang lurus ke samping, jika lengan kanan lurus ke samping kanan maka tolehan ke samping kanan dan jika lengan kiri lurus ke samping kiri maka tolehan juga ke kiri melihat ujung jari-jari tangan. Posisi bahu condong ke kiri dan pinggul condong ke kanan. Kedua kaki mendhak dan kedua lutut membuka membentuk seperti huruf $\mathrm{O}$.

Gerakan ini dilakukan arah sebaliknya). Menyimbolkan membersihkan penghalang. Artinya setiap kehidupan pasti ada penghalang dan kita harus bisa menghilangkan penghalang tersebut dengan cara berdoa dan berusaha semampunya, agar dibukakan jalan oleh Tuhan Yang Maha Esa. Penghalang atau rintangan dalam kehidupan untuk menuju hidup yang lebih baik, pasti akan dialami setiap manusia. Penghalang tersebut bisa 
datang dari mana dan dari siapapun, sebagai manusia kita sebaiknya menyikapi halangan atau rintangana tersebut dengan baik dan bijaksana. Jadikan penghalang tersebut sebagai motivasi dan semangat untuk selalu menjadi manusia yang sabar, ikhlas dan kuat serta selalu berserah diri kepada Tuhan. Karena dengan kita berdoa maka Tuhan akan membukakan jalan dan hidayahnya untuk kita agar menjadi manusia yang lebih baik lagi (Priyadi, wawancara 01-02-2019).

c. Singget (Kedua lengan dibuka kesamping dengan posisi lengan kanan di atas posis jari-jari menghadap bawah dan lengan kiri di bawah posisi jari menghadap atas. Kemudian pergelangan tangan kanan bertemu dengan punggung pergelangan tangan kiri ditarik menjadi satu dan ditekuk membentuk siku-siku di depan dada. Dengan posisi jari-jari tangan kanan menghadap keatas dan jari-jari tangan kiri menghadap ke bawah posisi jari-jari nyempurit. Tolehan kepala mengikuti pergelangan tangan dan badan menghadap lurus ke depan. Kedua kaki mendhak, posisi tungkai kanan di depan tungkai kiri, jari kaki nyelekenting dan tungkai kiri napak di belakang). Menyimbolkan baik dan buruk, di Jawa disebut milah milih olo lan becik (memilih baik dan buruk). Mempunyai makna yaitu sifat-sifat manusia didunia ada baik dan buruk, yang mana sebagai manusia harus bisa memilih hal-hal yang baik untuk dijalankan dan meninggalkan hal-hal yang buruk.
Dalam pewayangan Jawa simbol baik dan buruk dapat digambarkan dengan banyak cerita salah satunya adalah cerita Mahabarata. Mahabarata adalah sebuah kitab yang menceritakan tentang anak-anak Pandu dan anakanak Raja Destrarastra. Kelima anak Pandu yang disebut Pandawa menggambarkan tentang kebaikan yang mempunyai sifat-sifat sabar, ikhlas dan pemaaf. Dan keseratus anak Raja Desrtarastra yang biasa disebut Kurawa menggambarkan tentang keburukan yang mempunyai sifat iri, dengki, sombong dan angkuh. Para Pandawa selalu sabar jika mengalami cobaan baik dari Kurawa atau cobaan dari orang lain, mereka juga selalu pemaaf jika lawan-lawannya berbuat salah kepada mereka. Sebagai manusia kita sebaiknya mencontoh dari sifat-sifat Pandawa yang sabar, ikhlas dan pemaaf dalam menghadapi berbagai cobaan yang datang silih berganti. Jika kita dapat melakukan hal-hal yang baik kita akan dapat hidup dengan damai dan bahagia (Priyadi, wawancara 01-022019).

d. Mlampahngloro (Lengan kiri ditekuk di depan pusar telapak tangan menghadap ke bawah, lengan kanan ditekuk di depan pusar dengan posisi telapak tangan menghadap atas. Badan lebih condong ke depan mayuk, tolehan kepala mengikuti tangan kanan. Kedua kaki mendhak, tungkai kanan di depan napak dan tungkai kiri di belakang posisi ujung kaki jinjit). Menyimbolkan roda kehidupan, yang artinya bahwa roda kehidupan 
manusia kadang di atas dan kadang dibawah.

e. Nogo mangap (Kedua pergelangan tangan saling menempel dengan posisi pergelangan tangan kiri berada di atas dan pergelangan tangan kanan di bawah dan menghadap serong ke kiri. Posisi dadan menghadap serong kiri, tolehan kepala mengikuti pergerakan jari-jari yang berada di atas. Kedua kaki mendhak, tungkai kiri berada di depan dan tungkai kanan berada di belakang dengan posisi keduanya napak). Menyimbolkan tolak balak, mempunyai makna bahwa untuk menangkal bahaya kita harus selalu ingat dengan Tuhan Yang Maha Esa, agar sesuatu yang buruk tidak terjadi.

f. Mlampah prapatan (Kedua lengan diayun ke depan dan ke belakang secara bergantian. Tolehan kepala ke kanan dan ke kiri mengikuti gerak lengan yang diayun ke depan, badan menghadap ke depan dan kedua kaki mendhak. Kedua tungkai mengikuti pergerakan lengan, jika lengan kanan di depan tungkai kiri berada di depan dan jika lengan kiri di depam maka tungkai kanan juga di depan). Menyimbolkan papat limo pancer. Mempunyai makna yakni dalam kepercayaan Jawa sifat manusia ada 4 nafsu dan 1 hawa (Ammarah, Lawwamah, Supiyah/ Mulhima dan Muthmainnah). Dimana jika kita ingin menjadi manusia yang baik kita harus mampu mengendalikan sifat-sifat yang ada pada diri manusia. Dengan cara selalu mendekatkan diri kepada Tuhan Yang Maha Esa.

\section{Bagian 2 (Inti)}

Pada bagian kedua menggunakan gendhing jula-juli yang memiliki suasana rasa agung, riang lugas yang didukung dengan ragam gerak yaitu: singget, tanjak, mlampah lobo, mlampah nyiji kerep, kencrong. Pada bagian inti gerak-gerak tari ini mempunyai makna kehidupan atau perjalanan hidup manusia di dunia. Yang artinya manusia hidup di dunia pasti melalui banyak cobaan, halangan dan rintangan. Oleh sebab itu, sebagai manusia kita harus dapat menghadapi semua cobaan dengan sabar dan ikhlas serta tidak lupa selalu berdoa kepada Tuhan untuk meminta petunjuk dan jalan keluar yang terbaik.

Jalan hidup manusia pasti berbedabeda tergantung manusia tersebut menjalaninya. Kebanyakan orang akan memilih hidup dengan baik dan bahagia, agar dapat hidup dengan bahagia manusia pasti akan proses yang panjang dan menghadapi berbagai rintangan dan halangan. Dari proses tersebutlah yang akan menjadikan manusia untuk belajar dan berusaha untuk menjalani hidup dengan baik (Edi, wawancara 31-01- 2019). Pada bagian ini gerak-gerak yang terlihat tegas dan patah-patah, hal ini dapat dilihat dalam uraian gerak-gerak, yakni:

a. Srisik/trisik (Posisi lengan kanan berada di atas dan lengan kiri di bawah, kemudian kedua lengan ditarik menjadi satu dan ditekuk di depan ulu hati dengan posisi jari-jari kanan menghadap ke atas dan jari kiri menghadap ke bawah. Posisi badan tegak lurus menghadap serong kiri, pandangan melihat jari-jari kanan. Posisi tungkai kanan di depan dengan 
jari kaki nyelekenting dan tungkai kiri di belakang napak, kemudian berputar ke kanan). Menyimbolkan hubungan kolase kebawah seimbang. Artinya bahwa kita sebagai manusia harus mempunyai hubungan yang baik dengan Tuhan dan sesama.

b. Tanjak (Lengan kanan ditekuk ke atas sejajar dengan kepala membentuk sikusiku dengan jari-jari lurus ke samping kanan. Lengan kiri ditekuk ke arah depan sedikit ke bawah sejajar dengan dada dengan jari-jari menghadap ke atas. Badan condong ke arah kanan, pandangan mata lurus menghadap ke depan. Tungkai kanan di depan dan tungkai kiri di belakang keduanya napak). Menyimbolkan siap menerima yang terjadi. Bermakna bahwa kita manusia harus mempunyai rasa siap, sigap dengan apapun yang akan terjadi baik ataupun buruk.

c. Mlampah lobo (Lengan kanan lurus ke samping kanan bawah sejajar dengan pinggang, lengan kiri ditekuk ke atas dengan telapak tangan menghadap atas sejajar dengan kepala. Tolehan kepala mengikuti tangan kanan. Kedua kaki mendhak, tungkai kanan di depan gejug dan tungkai kiri di belakang napak). Menyimbolkan siap menerima pemberian apa yang dicari. Mempunyai makna bahwa apa yang kita cari dengan tekun dan kesabaran akan memperoleh hasil baik, namun demikian apabila terjadi sebaliknya kita harus siap lapang dada untuk menerima hal tersebut.

d. Mlampah nyiji kerep (Kedua lengan lurus di depan pusar telapak tangan kiri menghadap ke atas dan telapak tangan kanan menghadap ke bawah. Badan tegap menghadap ke depan, tolehan kepala mengikui tangan. Tungkai kanan napak di depan dengan jari nyelekenting, tungkai kiri napak di belakang). Menyimbolkan jalan hidup yang bertahap. Artinya bahwa untuk menuju keberhasilan perlu proses perjalanan kehidupan.

e. Kencrongan (Kedua lengan ditekuk di atas bahu dengan posisi ridong sampur atau memegang sampur. Posisi badan mayuki ke depan dan menghadap serong kiri, tolehan kepala menghadap serong kiri. Tungkai kanan di depan napak dan tungkai kiri napak di belakang tungkai kanan). Menyimbolkan siap memikul beban hidup. Mempunyai makna bahwa manusia hidup harus siap dengan beban yang akan dijalani apapun itu agar menjadi manusia yang kuat hati.

\section{Bagian 3 (Penutup)}

Bagian ketiga atau bagain penutup menggunakan gendhing suluk yang memiliki rasa agung dan wibawa yang didukung dengan ragam gerak: bedhayan gajah oleng, menthang prapatan, ukel, songgo nompo loro, mlampah lombo. Dan dilanjutkan dengan gendhing srepeg suroboyo yang memiliki suasana gendhing gembira dengan ragam gerak: tumpang tali jombangan, lembeyan, mlampah medot. Gerak-gerak tersebut mempunyai simbol tentang penyelesaian atau jalan keluar. Yang artinya walaupun cobaan dan bahaya datang, kita harus menghadapinya dengan sabar, yakin dengan keteguhan hati agar 
semua masalah yang datang dapat terselesaikan dengan baik. Menurut Edi, Tuhan tidak ada memberikan cobaan diluar batas kemampuan umatnya, dan tuhan juga tidak akan memberikaan cobaan tampa jalan keluar yang baik. Yang perlu kita lalukan adalah berdoa dan berusaha semampu kita untuk menghadapi cobaan tersebut, setelah itu serahkan kepada Tuhan untuk memberikan jalan yang terbaik untuk umatnya (Edi, wawancara 31-012019).

Gerak-gerak pada bagian penutup yang menyimbolkan penyelesaian ataujalan keluar lebih banyak menggunakan gerakgerak yang tegas dan dinamis, hal ini menggambarkan keberhasilan manusia dalam menyelesaikan masalah.

a. Bedhayan gajah oling (Kedua lengan menthang ke samping sejajar dengan pinggang dengan posisi jari ngithing. Kaki mendhak dan badan menghadap ke depan, tolehan kepala ke depan. Kedua tungkai napak tungkai kanan di depan tungkai kiri di belakang). Menyimbolkan cobaan, dalam Jawa disebut dengan olo becik gilor gumanti (baik buruk silih berganti), mempunyai makna bawha semua hal baik atau hal buruk yang terjadi dihidup manusia selalu silih berganti (Setu, wawancara 29-9-2018).

b. Mentang prapatan (Lengan kanan lurus ke samping bawah sejajar dengan pinggang lengan kiri di depan cetik. Badan mayuk ke depan, tolehan kepala mengikuti lengan yang lurus ke samping. Tungkai kiri gejug di belakang tungkai kanan). Menyimbolkan tolak balak 4 penjuru (utara, timur, selatan, barat). Maknanya yakni bahaya bisa datang dari berbagai arah, dengan demikian setiap melangkah harus selalu waspada dan penuh kesadaran jangan sampai terlena dan serta meninggalkan rasa tinggi hati atau sombong.

c. Ukel (Pergelangan tangan kanan diukel di depan bahu kiri dan lengan kiri lurus ke bawah menempel paha. Posisi kedua tumit menempel membuka 45 derajat, kepala mengikuti pergelangan yang di ukel). Menyimbolkan nyiwake sing olo. Maknanya manusia harus bisa memilih yang baik dan buruk serta membuang hal yang buruk dari dalam diri kita.

d. Songgo nompo loro (Kedua lengan ditekuk didepan wajah membentuk siku-siku dan kedua telapak tangan menghadap atas. Tungkai kanan di depan jari-jari nyelekenting, tungkai kiri napak di belakang napak. Badan mendhak dan menghadap ke kiri, kepala bergerak seperti angka 8 dari bawah ke atas). Menyimbolkan memohon pencerahan. Maknanya bahwa manusia harus senantiasa ingat kepada yang di atas untuk memohon pencerahan dan kelancaran dalam menjalani hidup di dunia.

e. Mlampah lombo (Kedua lengan menthang ke samping sejajar dengan pinggang dan jari-jari ngruji. Badan tegap menghadap ke depan, tolehan kepala ke kanan kiri menyesuaikan langkah kaki. Kedua tungkai seperti berjalan ditempat). Menyimbolkan mantep, jejeg pendirian. Yang artinya bahwa manusia harus mempunyai 
pendirian yang tetap dalam mengambil keputusan, dalam hal ini dibutuhkan ketegasan dan tekad.

f. Tumpang tali jombangan (Jari-jari tangan kiri ngruji menghadap depan dan lengan kanan berada di atas lengan kiri dengan jari-jari menghadap ke samping kiri. Tungkai kanan gejug di belakang dan tungkai kiri napak di depan. Badan serong kiri dan kedua kaki mendhak). Menyimbolkan ngudari rewet. Artinya manusia harus mampu menyelesaikan semua masalah yang dihadapi disertai kesabaran dan kebijakan sehingga tercapai yang diharapkan.

g. Lembeyan (Kedua lengan diayunkan ke depan dan ke belakang secara bergantian, kedua tungkai mengikuti pergerakan lengan, jika lengan kanan di depan tungkai kiri berada di depan dan kebalikanya. Badan menghadap ke depan, tolehan kepala menoleh ke kanan dan ke kiri mengikuti lengan yang di depan). Menyimbolkan enteng abot dilakoni (ringan berat dilakukan). Artinya manusia harus mampu menjalani hidup sabar dan menerima apa adanya yang dalam pemahaman masyarakat Jawa sumerah.

h. Mlampah Medot (Kedua lengan lurus di depan pusar telapak tangan kiri menghadap ke dalam dan telapak tangan kanan menghadap ke luar. Posisi jari tungkai kanan nyelekenthing di depan dan tungkai kiri napak di belakang. Posisi badan mendhak menghadap ke depan dan tolehan kepala mengikuti pergerakan pergelangan tangan). Menyimbolkan rasa ragu, penuh pertimbangan sebelum melakukan sesuatu hal.

Di atas merupakan simbol dan makna yang terdapat dalam gerak tari Mayang Rontek yang garis besarnya mengungkapakan tentang kehidupan manusia di dunia. Gerak-gerak di atas dilakukan 2x8 hitungan dengan makna bahwa di dunia ini semua ciptaan Tuhan diciptakan berpasangan, laki-laki perempuan, siang-malam, kiri-kanan, atasbawah, hidup-mati.

Makna simbolis yang tersirat dalam bentuk struktur sajian secara utuh maupun simboli-simbol yang dihadirkan pada vocabuler gerak tertentu dalam tari Mayang Rontek tersebut merupakan perwujudan dari nilai wigati dari isi atau pesan yang disampaikan oleh sang koreografer. Hal ini seiring dengan tanggapan beberapa seniman dan pengamat seni di kabupaten Mojokerto yang menyatakan bahwa karya tari Mayang Rontek merupakan sebuah ekspresi yang menginterpretasikan nilai filosofi Jawa dalam hal ini yang terkandung dalam sejarah pengantin Mojoputri yang diyakini oleh masyarakat Mojokerto sebagai wujud doa dan harapan (Priyadi, wawancara 01-022019).

\section{MAKNA SIMBOLIS IRINGAN DAN SYAIR DALAM TARI MAYANG RONTEK}

Iringan tari Mayang Rontek menggunakan gamelan lengkap Jawa Timur laras slendro, selain menggunakan gamelan iringan tari Mayang Rontek juga menggunakan terbangan, dikarenakan faktor lingkungan yang mana masyarakat Mojokerto lebih dominan beragama islam 
yang disetiap masjid pasti diajarkan musik terbangan atau rebana, yang dapat memunculkan gerak-gerak yang dinamis dan sigrak (Setu, wawancara 28- 03-2018).

Menurut Maryono yang mengutip pendapat Soedarsono, menyatakan bahwa musik dalam tari bukan hanya sekedar iringan, tetapi musik adalah partner tari yang tidak boleh ditinggalkan. Realita hanya sedikit tarian yang tidak menggunakan iringan musik, tetapi ritme dan nada-nada sebagai elemen dasar musik yang dihasilkan penari dapat dijadikan pijakan garapan tari seorang koreografer. Bagaimanapun bentuk pertunjukannya tari ternyata tidak dapat lepas sama sekali dengan kehadiran musik (2015:65).

Iringan tari Mayang Rontek terdiri dari beberapa gendhing Jawa Timur, yaitu: Giro Jaten, Terbangan/Hadrah/Rebana, Julajuli, dan Srepek Suroboyo. Gendhing Giro Jaten biasanya digunakan untuk prosesi temu pada manten Mojo Putri. Gendhing Giro Jaten mempunyai arti yang dalam yaitu, "Giro dalam bahasa Jawa berati udan (hujan)" dan "Jaten dalam bahasaa Jawa berarti temenan (beneran)", jadi dalam bahasa Jawa Giro Jaten berarti udan temenan (hujan beneran). Maksudnya adalah seorang pengantinmelakukan pernikahan untuk tujuan yang baik yaitu ingin menghindari hal yang buruk seperti maksiat, ingin memperoleh keturunan (anak) dan menjalankan kehidupan yang bahagia dengan keluarga barunya. Maka gendhing Giro Jaten digunakan untuk mengiringi prosesi temu manten yang akan memulai kehidupan yang baru di masa depan, selain itu gendhing Giro Jaten mempunyai rasa yang agung yang cocok untuk acara temu manten yang sakral dan agung (Priyadi, wawancara 12-11-2018). Dalam Tari Mayang Rontek menggunakan gendhing Giro Jaten dikarenakan tarian tersebut di pentaskan saat acara bedhol manten Mojoputri dan agar mendukung suasana dalam tari yang terasa lebih agung dan mantep.

\section{MAKNA SIMBOLIS KOSTUM DALAM TARI MAYANG RONTEK}

Kostum merupakan pakaian yang digunakan penari. Kostum merupakan pendukung tari yang sangat penting yang berfungsi untuk membedakan tokoh satu dengan yang lain, mendukung karakter tokoh. Kostum tari Mayang Rontek mengacu pada Mojoputri yang disederhanakan. Pada awalnya hiasan pada kepala menggunakan jilbab, kebaya panjang warna kuning dan jarik, hal tersebut mempunyai pengaruh dari masuknya ajaran islam. Kemudian oleh Setu jilbab diganti dengan kain penutup gelung, dengan maksud agar memudahkan penari untuk bergerak dan ditambah kain wolo, kain wolo adalah bokongan yang terbuat dari kain kaca atau satin.

Warna merupakan komponen yang penting, karena warna merupakan simbolisasi sifat, karakter dan penegasan suasana. Dalam kostum tari Mayang Rontek warna sangat penting karena menyimbolkan sesuatu yang terkait dengan makna cara manusia menjalani hidup didunia ini dengan baik. Dari awal terciptanya tari Mayang Rontek hingga sekarang kostum yang digunakan selalu menggunakan kebaya lengan panjang dengan warna kuning, menurut Setu warna 
kuning merupakan simbol dari rasa kasih sayang.

\section{PENUTUP}

Garap tari Mayang Rontek berawal dari manten Mojoputri, dimana Machmoed Zain ingn melihat sebuah tari penyambutan atau hiburan setelah temu manten agar tidak terkesan sepi, Setu sebagai koreografer dan seniman lain mencoba mencari beberapa refrensi tentang Mojoputri dari beberapa sumber yaitu buku, relief dan meditasi untuk mendapatkan informasi. Penggarapan dimulai dengan memilih penari-penari, kemudian penggarapan vocabuler gerak dan musik tari yang diambil dari beberapa gendhing yang sudah ada di Jawa Timur.

Tahun 1993 lahirlah tari Mayang Rontek dan dipentaskan dalam acara mantenan di Mojoputri, seiring berjalannya waktu pemerintah juga ingin mempunyai sebuah kesenian yang menjadi ciri khas dari kabupaten Mojokerto selain itu masyarakat juga sangat meneima tari Mayang Rontek di Mojokerto sebagai tari penyambutan, maka tahun 1996 tari Mayang Rontek disahkn menjadi tari khas kabupaten Mojokerto dibawah pemerintahan bupati Mahmoed Zain. Tari Mayang Rontek merupakan tarian yang bertemakan doa dan harapan agar depat menjalani hidup dengan baik, tari ini biasanya ditarikan oleh remaja putri yang bisa tunggal ataupun kelompok selain itu dalam acara HUT kabupaten Mojokerto sering ditarikan massal oleh pelajar seMojokerto. Para penari menggunakan rias cantik dengan kostum yang cantik juga seperti, kebaya panjang, jarik, kemben, rapek, pedang-pedangan, wolo, sabuk, sampur dan menggunakan rontek diatas gelung. Gerak dan musik menggunkan yang gerak dan musik yang sudah ada sebelumnya kemudian dikembangkan dan diubah sedikit untuk menjadi gerak dan musik baru. Tari ini menggunakan alat musik rebana yang membuat tarian ini lebih dinamis tetapi tetap lembut.

Gerak, musik dan syair, kostum, penari dan judul dalam tari Mayang Rontek mengandung makna simbolis yang dalam, yaitu tentang kehidupan manusia, dimana untuk menjadi manusia yang berakhlak baik pasti akan melalui proses yang panjang yang akan memberikan pelajaran dan pengalaman yang akan menjadikan kita menjadi manusia yang sabar, ikhlas dan kuat.

\section{DAFTAR PUSTAKA}

Bantolo, Matheus Wasi. 2002. Alusan Pada Tari Jawa.Tesis STSI Surakarta. Bening Khrisna,dkk. 2014. Laporan Akhir Repertoar 2 "Tari Mayang Rontek dari Mojokerto". Universitas Negeri Malang. Malang.

Hadi, Sumandiyo. 2005. Sosiologi Tari. Yogyakarta:Pustaka.

$$
\text { 2003. Aspek-aspek dasar }
$$
Koreografi Kelompok. Lembaga Kajian Pendidikan dan Humanihora Indonesia. Yogyakarta.

2007. Kajian Tari Teks dan Konteks. Pustaka Book Publisher. Yogyakarta. 
Herusatoto, Budiono. 2008. Simbolisme Jawa.

Penerbit Ombak, Yogyakarta. Koentjaraningrat. 2009. Pengantar ilmu Antropologi. PT RINEKA CIPTA. Jakarta.

Maryono. 2010. Pragmatik Genre Tari Pasihan Gaya Surakarta. Penerbit: ISI Press Solo. 2015. Analisa Tari. Penerbit: ISI Pres Solo.

Md, Slamet. 2016. Melihat Tari. Citra Sain. Lembaga Pengkajian dan Konservasi Budaya Nusantara. Karanganyar.

Murgiyanto, Sal. 1993. Ketika Cahaya Merah Memudar. PT Anem Kosong Anem. Jakarta.

Pramutomo, R.M. 2008. Etnokoreologi Nusantara (Batasan Kajian, Sistematika, dan Aplikasi Keilmuan). ISI Pres. Surakarta.

Piliang, Yasraf Amir. 2003. Hipersemiotika: Tafsir Cultural Studies atas Matinya Makna. Jalasuta. Yogyakarta.

Rocye, Anya Peterson. 1991. Antropologi Tari. Oleh Agus Tasman. Indiana University Press.

Sedyawati, Edi. 1984. Tari, Tinjauan dari Berbagai Segi. PT Dunia Pustaka Jaya. Jakarta Pusat.

Soedarsono. 2002. Seni Pertunjukan Indone- sia Di Era Globalisasi. Yogyakarta: Gadjah Mada University Press. , 1985. Peranan Seni Budaya dalam Sejarah Kehidupan Manusia Komunitas dan Perubahannya. Yogyakarta. , 1986. Elemen-Elemen Dasar Komposisi Tari. Lagaligo Fakultas Kesenian Institut Seni Indonesia. Yogyakarta.

Supanggah, Rahayu. 2009. Bothekan Karawitan II: Garap. ISI Press. Surakarta.

Supriyant. Henri, dkk. 1997. Upacara Adat Jawa Timur. Dinas Pariwisata dan Kebudayaan Privinsi Daerah Tingkat I Jawa Timur. Surabaya.

Widyastutieningrum, Sri Rochana dan Wahyudiarto, Dwi. 2014. Pengantar Koreografi. ISI Press. Surakarta.

\section{DISKOGRAFI}

Smansasoo Project. 2014. “ Tari Mayang Rontek," VCD bahan ajar muatan lokal di sekolah se-kabupaten Mojokerto, koleksi penulis.

\section{Narasumber}

Setu (57 tahun). Dusun Losari, Desa Sidoharjo, Gedeg, Mojokerto. sebagai koreografi tari Mayang Rontek.

Sumarji (58 tahun). Desa Dinoyo, Kecamatan Jati Rejo, Mojokerto. Sebagai pemusik tari Mayang Rontek. 
Budiarti (50 tahun). Jalan Pangrango Gg 3 No. 3 Perum Kedungdung Indah Magersari, Mojokerto. Guru tari di SMPN 1 Jetis Kabupaten Mojokerto.

Sandra Wahyuningtyas (26 tahun). Dusun Karangasem, Desa Pagerluyung, Gedeg, Mojokerto. Penari dan rias manten.

Priyadi (58 tahun). Japanan, Kemlagi, Mojokerto. Seniman dalang Mojokerto.
Anita Anju, S.Pd. M.Pd (40 tahun). Perum Bloto, Mojokerto. Mantan penari Mayang Rontek dan seniman Mojokerto.

Drs. H Eko Edi Susanto., Msi. (61 tahun). Dusun Sukodono RT 01/RW 02, Desa Canggu, Jetis, Kabupaten Mojokerto. Mantan Kepala Dinas Kota Mojokerto dan Pimpinan Ludruk Karya Budaya Mojokerto. 